\title{
Survival and Mortality of Patients with Hyponatremia in Intensive Care Units: A Retrospective Study of 327 Patients Hospitalized at Sylvanus Olympio University Hospital
}

\author{
Eyram Yoan Makafui Amekoudii, *, Kossi Akomola Sabi ${ }^{1}$, Komlan Georges Tona ${ }^{1}$, \\ Badomta Dolaama $^{1}$, Béfa Noto-Kadou-Kaza ${ }^{1}$, Epiphane Kola $^{1}$, Bayaki Saka ${ }^{2}$ \\ ${ }^{1}$ Department of Nephrology and Hemodialysis, University of Lome, Lome, Togo \\ ${ }^{2}$ Department of Dermatology and Venerology, University of Lome, Lome, Togo
}

Email address:

eyramyoan@gmail.com (E. Y. M. Amekoudi)

${ }^{*}$ Corresponding author

\section{To cite this article:}

Eyram Yoan Makafui Amekoudi, Kossi Akomola Sabi, Komlan Georges Tona, Badomta Dolaama, Béfa Noto Kadou Kaza, Epiphane Kola, Bayaki Saka. Survival and Mortality of Patients with Hyponatremia in Intensive Care Units: A Retrospective Study of 327 Patients Hospitalized at Sylvanus Olympio University Hospital. American Journal of Clinical and Experimental Medicine. Vol. 7, No. 1, 2019, pp. 35-41. doi: 10.11648/j.ajcem.20190701.15

Received: April 23, 2019; Accepted: June 10, 2019; Published: June 26, 2019

\begin{abstract}
Hyponatremia is recognized as the most common electrolyte disorder in hospitalization services. It is associated in the literature with a prolongation of the hospitalization with a variable mortality according to comorbidities and etiologies. In Togo, although empirically noted, this excess mortality has never been demonstrated. The objective of our study was to determine the survival and mortality of patients with hyponatremia in the intensive care units of the Sylvanus Olympio Hospital Center (CHU SO). We collected 2802 patients over the period from January 1, 2015 to December 31, 2016. Of these patients, 327 included patients, of whom 79 had hyponatremia, had a frequency of $23.6 \%$. The prevalence of hyponatremia was $2.8 \%$. The average of natremia was $126.3 \pm 6.8 \mathrm{mmol} / \mathrm{L}$ with extremes of $100 \mathrm{mmol} / \mathrm{L}$ and $134 \mathrm{mmol} / \mathrm{L}$. The mean age of patients was $52.3 \pm 18.2$ years (range: 18 to 92 years) with a sex ratio (M / F) of 1.5. The most common comorbidities were high blood pressure $(32.9 \%)$ and diabetes $(13.9 \%)$. The most common etiology was neurological $(26.6 \%)$, renal $(20.3 \%)$ and infectious (19\%). The average duration of hospitalization was 11 days. The probability of survival after 11 days was $49 \%$, with excess mortality depending on the severity of hyponatremia. Because of its importance hyponatremia appears as a cause of mortality. This study provides the prognosis of patients in intensive care and urges the implementation of ionogram monitoring technique.
\end{abstract}

Keywords: Hyponatremia, Epidemiology, Mortality, Survival, Sub-saharan Africa

\section{Introduction}

Hyponatremia is the most common hydro electrolytic disorder in intensive care $[1,2]$. It may be asymptomatic, of incidental or symptomatic discovery with diversified clinical signs, nonspecific and often entangled with those of the pathology in question [3]. It is a factor of bad prognosis, significantly increasing mortality and its treatment is a challenge for the resuscitator $[1,4]$. Its difficulties of care are related to the plurality of mechanisms of installation with as major risk of complications: an irreversible neurological attack [1]. Epidemiological data are diversified according to different regions of the world [5-8]. In the western series, there is a prevalence of $18 \%$ in a multicenter study between France, Switzerland, and the United States [9]. In Africa, in the Republic of Côte d'Ivoire [10], a prevalence of $48 \%$ was found among Cardiology patients. In Togo, to our knowledge, no such study has been carried out despite an empirical finding that this hydro electrolytic disorder is 
life-threatening for patients. Therefore, it seems necessary to carry out this study with goal is to determine the survival and mortality of patients with hyponatremia in adult intensive care units at the Sylvanus Olympio University Hospital Center (CHU-SO) in Lomé.

\section{Methodology}

\subsection{Framework and Method}

Multipurpose resuscitation, medical resuscitation, and the CHU-SO burnt department were used as a framework. This was a descriptive and analytical study of a retrospective cohort of hospitalized patients in these three departments from January 1, 2015 to December 31, 2016, for a period of twenty-four (24) months. All patients registered in the hospital registers of the three departments with hyponatremia at the first dose of serum sodium (performed within 48 hours of admission) were included. Patients with hyponatremia < 15 years of age were not included. Data was collected from patient records using a survey form. The variables studied were: socio-demographic characteristics (age, gender), comorbidities (mainly cardiovascular, neurological, endocrine, nephrological, pulmonary, digestive, HIV immunodepression and surgical), clinical characteristics (blood pressure, condition of hydration), biological, the origin of the patient, and the probable etiologies of hyponatremia.

\subsection{Operational Definitions}

Patients' provenance was used to assess the probable place of hyponatremia and to distinguish two groups of patients: community hyponatremia (patients admitted with hyponatremia) and hospital hyponatremia (patients with hyponatremia during treatment, hospitalization.)

The normal value of natremia ranges from $135 \mathrm{mmol} / \mathrm{l}$ to $145 \mathrm{mmol} / \mathrm{l}$. According to the severity, moderate hyponatremia (serum sodium concentration between 120 $\mathrm{mmol} / \mathrm{l}$ and $135 \mathrm{mmol} / \mathrm{l}$ ) and severe hyponatremia (serum sodium concentration below $120 \mathrm{mmol} / \mathrm{l}$ ) were defined. The serum retained for the analysis of the biological data was the natremia at the entrance of the patient is the natremia achieved within 48 hours (maximum) following are admission. Normal chlorination was defined between 98 $\mathrm{mmol} / \mathrm{l}$ and $107 \mathrm{mmol} / \mathrm{l}$.

Renal failure was defined for an estimated Glomerular Filtration Rate (eGFR) of less than $60 \mathrm{ml} / \mathrm{min} / 1.73 \mathrm{~m} 2$. EGFR is calculated by calculating serum creatinine clearance based on the simplified MDRD (Modification of Diet in Renal Diseases) formula. The state of hydration of the patient was assessed by clinical criteria and defined as follows: hypovolemic (presence of dry mucous membranes, skin fold, hypotension, thirst); hypervolemic (edema of the face and lower limbs, ascites, high blood pressure); euvolemic (absence of edema, ascites, skin fold, thirst with blood pressure is normal).

One or more etiologies associated with hyponatremia have been identified as the probable cause (renal, pulmonary, cardiac, CNS, thermal burn and sepsis). Sepsis was defined by the association of a systemic inflammatory response syndrome (retained in association with at least two of the following signs: body temperature $>38^{\circ} \mathrm{C}$ or $<36^{\circ} \mathrm{C}$, heart rate $>90 \mathrm{bbm}$, rhythm respiratory $>20 / \mathrm{min}$ or hyperventilation to blood gases, leukocytes $>12000 / \mathrm{mm}^{3}$ or $<4000 / \mathrm{mm}^{3}$ ) with bacteremia confirmed at least biologically.

The evolution was based on the duration of hospitalization and the future of the patient. It was supportive (resulting in the patient's recovery or discharge from the intensive care unit to another department) or unfavorable (progressing to death.

\subsection{Data Processing}

The statistical analysis was carried out with the software RStudio version 3.3.2. It consisted of a descriptive analysis, a comparative analysis and the logistic regression.

In the descriptive analysis, the results were expressed in terms of size and percentage for qualitative or median and interquartile (IIQ) variables for the quantitative variables. In terms of comparative analysis, the statistical tests used were the Pearson Chi-square test or the Fisher exact test for qualitative variables and the Mann Whitney / Wilcoxon test for quantitative variables. The threshold of significance was set at 0.05 . Missing data were not considered in the analyzes. Univariate and multivariate logistic regression was performed to investigate factors associated with hyponatremia.

Regarding the analysis of survival, the event studied was: death. Patient follow-up time was expressed in days. It corresponds to the difference between the date of entry into the service and the date of exit or death. The latest news date was the date of the last visit or the date of the event. The date was December 31, 2016. For censorship: patients were censored (right censorship) when they were lost to follow-up, died, escaped (exited without medical agreement) or when they were transferred to another care center. We used survival data analysis to describe the occurrence of death in each hyponatremia group, and the Log-Rank test was used to compare the survival curves of patients with severe and moderate hyponatremia.

\subsection{Ethical Aspect}

All the medical information collected was anonymized before being transmitted to the investigations. The study was made according to the recommendations of the ethics committee of the University of Lomé and in accordance with national and local regulations.

\section{Results}

\subsection{Main Features}

During the study period, 2802 patients were enrolled in the three target services; 327 out of them had achieved 
natremia. Among the 327 patients, 71 had hypernatremia, 177 patients had normal natremia, and hyponatremia was objectified in 79 patients. The frequency of hyponatremia was $24.1 \%$. Its prevalence in the total population of resuscitation patients was $2.8 \%$. The mean age of the patients was 52.3 years with a median age of 52 [IQI 37-66 years], the extremes were 18 years and 92 years; $29.1 \%$ of patients were under 40 years old. Most patients came from hospitals, $62 \%$. The sex ratio was 1.5 . The two main comorbidities were high blood pressure $(32.9 \%)$ and diabetes $(13.9 \%)$ (Figure 1). Clinically: $48.1 \%$ of patients had neurological disorders in which $63.1 \%$ had consciousness alteration, $34.2 \%$ had coma and $15.8 \%$ had agitation and convulsions. The median systolic blood pressure was $130 \mathrm{mmHg}$ [IIQ $=110-160 \mathrm{mmHg}$ ] and the median diastolic was $80 \mathrm{mmHg}$ [IIQ $=70-90 \mathrm{mmHg}$ ]. The biological results are shown in Table 1 .

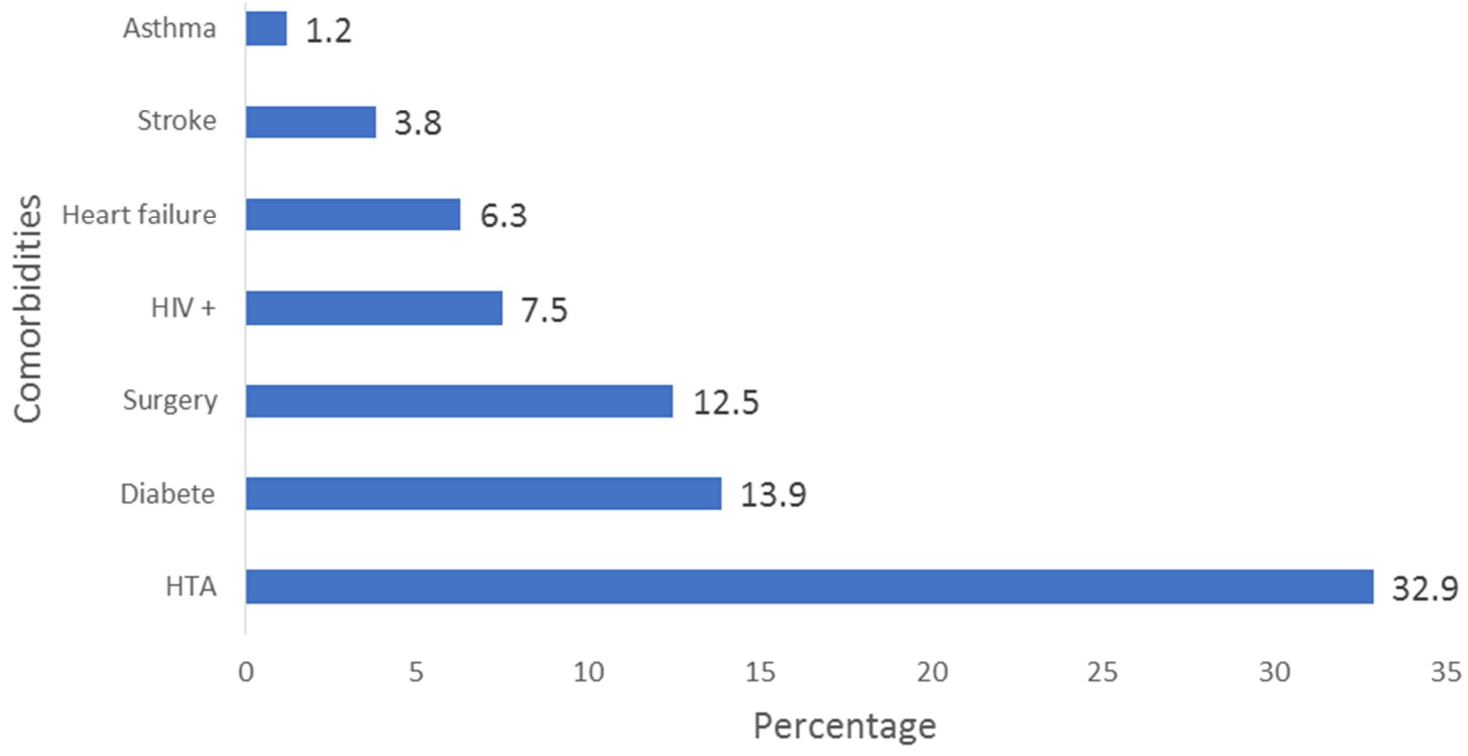

Figure 1. Distribution of patients by co-morbidities.

\subsection{Probable Etiologies, Associated Factors and Treatments}

In our series, $26.6 \%$ of patients had central nervous system disease and $5.1 \%$ had thermal burn and a heart affection. Two risk factors were associated with univariate hyponatremia:
Table 1. Distribution of patients according to biological parameters.

\begin{tabular}{lll}
\hline & \multicolumn{2}{l}{ Effective $(\mathbf{N}=\mathbf{7 9})$} \\
\cline { 2 - 3 } & $\mathbf{N}$ & $\mathbf{\%}$ \\
\hline Kaliemia (mmol/1) & 16 & 20.2 \\
Hypokaliemia & 53 & 67.1 \\
Normal & 10 & 12.7 \\
Hyperkaliemia & & \\
Chloremia (mmol/1) & 53 & 67.1 \\
Hypochloraemia & 24 & 30.4 \\
Normal & 2 & 2.5 \\
Hyperchloraemia & & \\
Blood glucose $(\mathrm{g} / \mathrm{l})$ & 8 & 10.1 \\
Hypoglycemia & 24 & 30.4 \\
Normal & 26 & 32.9 \\
Hyperglycemia & 21 & 26.6 \\
Not indicated & & \\
\hline
\end{tabular}

Table 2. Factors associated with hyponatremia in univariate Analysis $(N=256)$.

\begin{tabular}{|c|c|c|c|c|}
\hline & $\mathbf{n} / \mathbf{N}$ & OR & IC à $95 \%$ & P value \\
\hline Age (years) & & & & 0.3489 \\
\hline$<52$ & $41 / 144$ & 1 & & \\
\hline$\geq 52$ & $38 / 112$ & 1.29 & {$[0.76-2.20]$} & \\
\hline Gender & & & & 0.4848 \\
\hline Male & $47 / 144$ & 1 & & \\
\hline $\begin{array}{l}\text { Female } \\
\text { comorbidities }\end{array}$ & $32 / 112$ & 0.83 & {$[0.48-1.41]$} & \\
\hline Absence of comorbidities & & 1 & & \\
\hline Cardiac comorbidities & $26 / 104$ & 0.62 & {$[0.35-1.08]$} & 0.0944 \\
\hline Neurological comorbidities & $3 / 16$ & 0.50 & [0.11-1.60] & 0.2874 \\
\hline Diabetes & $11 / 29$ & 1.43 & {$[0.62-3.15]$} & 0.3831 \\
\hline Nephrology & $5 / 11$ & 1.93 & {$[0.54-6.59]$} & 0.2916 \\
\hline Pulmonary & $1 / 7$ & 0.37 & {$[0.02-2.19]$} & 0.3551 \\
\hline
\end{tabular}

renal etiologies and sepsis (Table 2). After adjusting for other factors in the initial model, renal disease and sepsis were associated with hyponatremia (Table 3 ). $88.6 \%$ of patients received saline serum and $32.9 \%$ received furosemide. Among 70 patients taking saline serum, $90 \%$ were normovolemic. 


\begin{tabular}{|c|c|c|c|c|}
\hline & $\mathbf{n} / \mathbf{N}$ & OR & IC à $95 \%$ & P value \\
\hline Vih & $6 / 15$ & 1.53 & {$[0.50-4.41]$} & 0.4325 \\
\hline surgery & $10 / 28$ & 1.28 & {$[0.54-2.87]$} & 0.5564 \\
\hline Provenance & & & & 0.7806 \\
\hline Community patients & $49 / 162$ & & & \\
\hline Hospital patients & $30 / 94$ & 1.08 & {$[0.62-1.87]$} & \\
\hline \multicolumn{5}{|l|}{ Neurological disorders } \\
\hline \multicolumn{5}{|l|}{ Lake of troubles } \\
\hline Alteration & $22 / 83$ & 0.90 & {$[0.42-1.94]$} & 0.7888 \\
\hline Coma & $10 / 28$ & 1.65 & {$[0.66-3.94]$} & 0.2686 \\
\hline Confusion & $2 / 2$ & - & - & - \\
\hline Stirring & $1 / 2$ & 2.70 & [0.11-69.53] & 0.4860 \\
\hline Convulsion & $5 / 15$ & 1.38 & [0.41-4.19] & 0.5824 \\
\hline \multicolumn{5}{|l|}{ Respiratory disorders } \\
\hline \multicolumn{5}{|l|}{ Lake of troubles } \\
\hline Distress & $0 / 3$ & - & - & - \\
\hline Desaturation & $0 / 3$ & - & - & - \\
\hline \multicolumn{5}{|l|}{ Renal disorders } \\
\hline Oliguria & $0 / 6$ & - & - & - \\
\hline Anuria & $4 / 10$ & 2.67 & {$[0.26-63.10]$} & 0.4474 \\
\hline kalemia & & & & 0.8265 \\
\hline Hypokaliemia & $16 / 55$ & 1 & & \\
\hline Normal & $53 / 173$ & 1.09 & {$[0.57-2.16]$} & 0.8089 \\
\hline Hyperkaliemia & $10 / 28$ & 1.35 & {$[0.51-3.55]$} & 0.5391 \\
\hline Chloraemia & & & & $<0.0001$ \\
\hline Hypochloraemia & $53 / 91$ & 1 & & \\
\hline Normal & $24 / 124$ & 0.17 & {$[0.09-0.31]$} & $<0.0001$ \\
\hline Hyperchloraemia & $2 / 41$ & 0.04 & {$[0.01-0.13]$} & $<0.0001$ \\
\hline Blood glucose & & & & 0.9515 \\
\hline Hypoglycemia & $8 / 30$ & 1 & & \\
\hline Normal & $24 / 85$ & 1.08 & {$[0.44-2.89]$} & 0.8691 \\
\hline Hyperglycemia & $26 / 88$ & 1.15 & {$[0.47-3.06]$} & 0.7638 \\
\hline Extracellular volume & & & & 0.1284 \\
\hline Decreased & $2 / 5$ & 1 & & \\
\hline Kept & $68 / 234$ & 0.61 & {$[0.10-4.74]$} & 0.5982 \\
\hline increased & $9 / 17$ & 1.69 & {$[0.22-15.45]$} & 0.6129 \\
\hline \multicolumn{5}{|l|}{ Etiologies } \\
\hline renal & $16 / 35$ & 2.10 & {$[1.01-4.34$} & 0.0455 \\
\hline Pulmonary & $2 / 8$ & 0.73 & {$[0.11-3.26]$} & 0.7058 \\
\hline Central nervous system & $21 / 99$ & 0.46 & {$[0.25-0.80]$} & 0.0079 \\
\hline Cardiac & $4 / 16$ & 0.72 & {$[0.20-2.16]$} & 0.5873 \\
\hline Thermal burn & $4 / 13$ & 0.98 & {$[0.26-3.12]$} & 0.9787 \\
\hline Sepsis & $15 / 31$ & 2.33 & {$[1.08-5.01]$} & 0.0296 \\
\hline Other & $26 / 54$ & 1.26 & {$[0.70-2.22]$} & 0.4275 \\
\hline
\end{tabular}

Table 3. Factors Associated with Hyponatremia in Multivariate Analysis.

\begin{tabular}{|c|c|c|c|c|c|c|}
\hline & \multicolumn{3}{|c|}{ Initial model } & \multicolumn{3}{|c|}{ Final model } \\
\hline & OR & IC at $95 \%$ & P value & ORa & IC at $95 \%$ & P value \\
\hline Extracellular volume & & & 0.3209 & & & \\
\hline Hypovolemia & 1 & & & & & \\
\hline Normal & 0.91 & [0.10-10.14] & 0.9349 & & & \\
\hline Hypervolemic & 2.31 & [0.19-33.68] & 0.5195 & & & \\
\hline \multicolumn{7}{|l|}{ Etiologies } \\
\hline Rénal & 2.83 & [1.10-7.39] & 0.0311 & 3.41 & {$[1.40-8.50]$} & 0.0073 \\
\hline Nervous & 0.70 & {$[0.32-1.50]$} & 0.3576 & & & \\
\hline Sepsis & 2.57 & [0.98-6.83] & 0.0552 & 2.72 & [1.13-6.76] & 0.0285 \\
\hline
\end{tabular}

\subsection{Survival of Patients with Hyponatremia and Mortality}

Over the total hospital stay 49 deaths related to hyponatremia were reported either a mortality of $62 \%$. In multivariate analysis, adjusted for other factors, hospital origin and diabetes were associated with death (Table 4). Diabetes $(\mathrm{OR}=0.19[0.04-074], \mathrm{p}=0.0237)$ as a protective factor for death and hospital origin $(\mathrm{OR}=2.82$ [1.01-8.58], $\mathrm{p}$ $=0.0493)$ as a risk factor. The median hospital stay in patients with hyponatremia was 11 days [IQI 5.0-20.5 days]. At 11 days of hospitalization, the probability of survival was $49.3 \%(95 \%$ CI $0.42-0.57)$ in patients with hyponatremia compared to $61.10 \%(95 \%$ CI $0.50-0.73)$ in patients with hyponatremia of patients in normo-natremia (Figures 2). 
Table 4. Factors Associated with death in multivariate analysis.

\begin{tabular}{|c|c|c|c|c|c|c|}
\hline & \multicolumn{3}{|l|}{ Initial model } & \multicolumn{3}{|c|}{ Final model } \\
\hline & OR & IC à $95 \%$ & P value & ORa & IC à $95 \%$ & P value \\
\hline \multicolumn{7}{|l|}{ Origin } \\
\hline Community & 1 & & & & & \\
\hline Hospital & 3.20 & [1.11-10.41] & 0.0387 & 2.82 & [1.01-8.58] & 0.0237 \\
\hline \multicolumn{7}{|c|}{ Cardiac etiology } \\
\hline No & 1 & & & & & \\
\hline Yes & 0.13 & [0.01-1.41] & 0.1182 & & & \\
\hline \multicolumn{7}{|l|}{ Diabetes } \\
\hline No & 1 & & & & & \\
\hline Yes & 0.18 & [0.03-0.75] & 0.0260 & 0.19 & {$[0.04-0.47]$} & 0.0493 \\
\hline
\end{tabular}

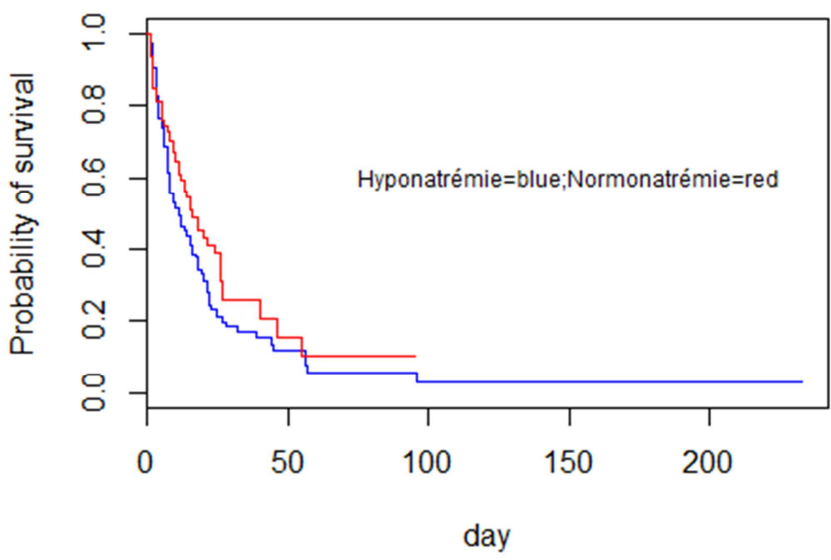

Figure 2. Survival curve in patients with hyponatremia and normo-natremia $(n=256)$.

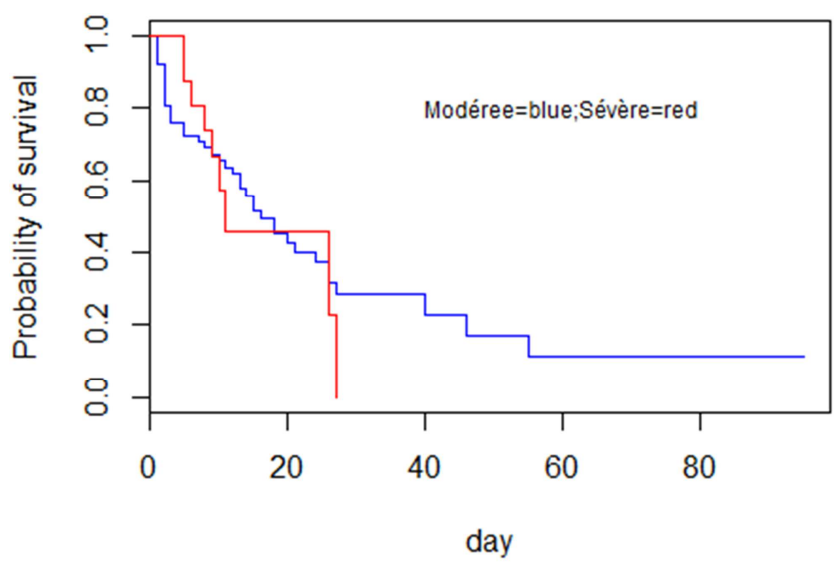

Figure 3. Survival curve in patients with moderate and severe hyponatremia $(n=79)$.

\section{Discussion}

The major limit of this work is related to the methodology and mainly to the retrospective nature. There were several missing data in the files that formed the basis of our study. In fact, these data are most often incomplete for biological or imprecise data for the determination of an antecedent, a symptom or a diagnosis. Only 334 cases out of 2809 patients, or $12 \%$ of patients admitted during the study period had at least one natremia. Despite the financial constraints that may exist (since most patients have no social coverage), this reflects the fact that in Togo, practitioners do not yet measure the importance of natremia in the patient's prognosis, where the interest of this study.

This work reveals that hyponatremia is associated with decreased survival in hospitalization. In our series, at 11-day, median length of stay for patients with hyponatremia, the probability of survival of patients was $49.3 \%$ while it was $62 \%$ in normonatremic patients.

To explain this pejorative prognosis, several avenues have been put forward, including that concerning the severity of the underlying pathology as Ketannaeh et al demonstrates so well in their work on hospital mortality [11]. This also explains why in our series of patients in intensive care, the mortality seemed very high contrary to the data of the literature which varied between $16 \%$ and $45 \%[7,12,13]$. Resuscitation patients are more pathological than those of an organ service because they generally have multi organ involvement. This argument has been defended by Bénnani et al who, after having demonstrated that hyponatremia is an independent factor of mortality, recognizes that its association with organ failure aggravates the patient's prognosis [7]. He, like others before him, underlined that the pejorative prognosis of hyponatremia was specific to certain patient groups such as cirrhotic, heart failure, comatose and delusional patients as reported by Ziescheng et al in a group of patients. of geriatric elderly subjects [14]. In addition, this prognosis depended on the severity of hyponatremia [7]. In our series, this last data seems to be emerging (Figure 3) without being confirmed $(\mathrm{p}<0.8)$ with a near-zero probability of survival after 25 days of hospitalization in patients with hyponatremia lower than $120 \mathrm{mmol} / \mathrm{l}$.

Regarding the etiologies and factors associated with hyponatremia, like Bennani et al [9], the comparison of our results with those of the other series is difficult to make considering the way in which our sample was recruited. outpatient care and other shares of secondary transfers from other CHU-SO services. Nevertheless, it shows a strong similarity with the data of the literature. We found $28.6 \%$ of neurological pathologies, $20.2 \%$ of renal pathologies and $5.1 \%$ of cardiac pathologies. Several authors have reported that diseases of the central nervous system constitute the main etiologies of hyponatremia $[15,16]$. This is explained by the alteration of the tubular reabsorption of sodium which is manifest during a cerebral lesion thus decreasing the sodic pool of the organism [15].

In multivariate analysis, the two determinants of hyponatremia found were renal etiologies $(p=0.04)$ and 
sepsis $(p=0.02)$. Are these affections the same as reserved prognoses? in contrast to sepsis, uremia has been identified by Bennani et al as a risk factor for mortality [7]. The factor associated with the death was the fact of being a patient from the hospital with a risk of 2.82 testifying the heaviness of patients from hospital. Hyponatremia is often more common in the hospital population [17]. Clayton et al [12] in their study comparing hyponatremia at admission and hyponatremia acquired during hospitalization, showed that hyponatremia developed in hospital stay was mainly iatrogenic, with a significantly higher frequency drug etiology by diuretics and infusion of hypotonic solutes resulting in dilution hyponatremia $[4,9,12]$.

The frequent involvement of drugs in the occurrence of severe hyponatremia is a reminder of the need for regular biological monitoring of natremia and renal function, especially since several potentially hyponatremic drugs are prescribed simultaneously [15].

The last hypothesis that explains this rapid decrease in survival in patients with hyponatremia is that management is late and poorly provided in means; and yet the link between the rapid and correct management of hyponatremia and the outcome of the patient has been well demonstrated by Yoshioka et al in a series of cardiological patients [18]. In this study, the risk of re-hospitalization at 30 days or death was significantly higher in patients with heart failure who had persistent hyponatremia compared to those whose serum sodium level had been normalized during hospital stay. There is also the question of the correct treatment in hyponatremia in Togo, at the time of vaptan and its derivatives Obviously this is dictated by the mechanism of occurrence that can sometimes be complex.

In our series, the frequency of hyponatremia in resuscitation services was $24.16 \%$. Hao et al found a prevalence of $17.5 \%$ in internal medicine hospitalization [8], like Andreas et al. in 2014 in a multicenter cohort performed in the United States, France and Switzerland, which had a prevalence of $18 \%$ [17]. These data contrast with those of Traore et al, who had found a prevalence of $48 \%$ at the Abidjan Heart Institute [10]. This variability is frequent in the literature depending on the study population. Nevertheless, the conclusion is clear, this hydro electrolytic disorder is preponderant in hospitalized patients.

\section{Conclusion}

Hyponatremia seriously affects the prognosis of the patient in intensive care. It decreases survival very quickly and causes high mortality. With all these arguments, practitioners must detect and correct it as soon as possible. It would be interesting to detect in a prospective cohort the practical attitudes of practitioners to hyponatremia and the impact on the prognosis of patients.

\section{Conflicts of Interest}

All the authors do not have any possible conflicts of interest.

\section{References}

[1] Quintard H, Facchini A, Gentelet C, Ichai C. Comment prendre en charge une dysnatrémie en neuroréanimation? Prat En Anesth Réanimation. avr 2018; 22 (2): 105-9.

[2] Roubille C, Jugant S, Jeantet G, Zerkowski L, Fesler P, Ribstein J. L'hyponatrémie, les examens paracliniques et l'interniste clinicien. Rev Médecine Interne. 2017; 38: A61.

[3] Passeron A, Dupeux S, Blanchard A. Hyponatrémie: de la physiopathologie à la pratique. Rev Médecine Interne. 2010; 31 (4): 277-286.

[4] Langlois PL, Bourguignon MJ, Manzanares W. L'hyponatrémie chez le patient cérébrolésé en soins intensifs: étiologie et prise en charge. Médecine Intensive Réanimation. 2016; 25 (5): 203-213.

[5] Olsson K, Öhlin B, Melander O. Epidemiology and characteristics of hyponatremia in the emergency department. Eur J Intern Med. 1 mars 2013; 24 (2): 110-6.

[6] Tamizifar B, Kheiry S, Fereidoony F. Hyponatremia and 30 days mortality of patients with acute pulmonary embolism. J Res Med Sci Off J Isfahan Univ Med Sci. août 2015; 20 (8): 777-81.

[7] Bennani SL, Abouqal R, Zeggwagh AA, Madani N, Abidi K, Zekraoui A, et al. Incidence, causes and prognostic factors of hyponatremia in intensive care. Rev Med Interne. 2003; 24 (4): 224-229.

[8] Hao J, Li Y, Zhang X, Pang C, Wang Y, Nigwekar SU, et al. The prevalence and mortality of hyponatremia is seriously underestimated in Chinese general medical patients: an observational retrospective study. BMC Nephrol. 31 oct 2017; 18 (1): 328 .

[9] Eckart A, Hausfater P, Amin D, Amin A, Haubitz S, Bernard $\mathrm{M}$, et al. Hyponatremia and activation of vasopressin secretion are both independently associated with 30-day mortality: results of a multicenter, observational study. J Intern Med. 2018.

[10] Traore F, Kouamé J, Ngoran K. Prévalence de l'hyponatrémie dans l'insuffisance cardiaque à l'institut de cardiologie. Abidjan. 2017; 22-30.

[11] Kettaneh A, Mario N, Fardet L, Flick D, Fozing T, Tiev K, et al. Mortalité hospitalière et durée de séjour des patients non programmés en médecine interne: valeur pronostique de paramètres biochimiques usuels à l'admission. Rev Médecine Interne. juill 2007; 28 (7): 443-9.

[12] Clayton JA, Le Jeune IR, Hall IP. Severe hyponatraemia in medical in-patients: aetiology, assessment and outcome. J Assoc Physicians. 2006; 99 (8): 505-511.

[13] Creusot M-L, Clos Prophette F. Etude rétrospective des hyponatrémies hospitalisées dans un service de médecine polyvalente sur 13 mois. 2014;

[14] Zieschang T, Wolf M, Vellappallil T, Uhlmann L, Oster P, Kopf D. The Association of Hyponatremia, Risk of Confusional State, and Mortality. Dtsch Arzteblatt Int. 16 déc 2016; 113 (50): 855-62. 
[15] Pokaharel M, Block CA. Dysnatremia in the ICU. Curr Opin Crit Care. déc 2011; 17 (6): 581-93.

[16] Chalela R, González-García JG, Chillarón JJ, ValeraHernández L, Montoya-Rangel C, Badenes D, et al. Impact of hyponatremia on mortality and morbidity in patients with COPD exacerbations. Respir Med. 2016; 117: 237-42.

[17] Joosen D a. WA, Zwietering NA, Bosch M, Stassen PM.
Characteristics and outcome of acute medical admissions with hyponatremia: even mild hyponatremia is associated with higher mortality. Acute Med. 2017; 16 (4): 156-63.

[18] Yoshioka K, Matsue Y, Kagiyama N, Yoshida K, Kume T, Okura $\mathrm{H}$, et al. Recovery from hyponatremia in acute phase is associated with better in-hospital mortality rate in acute heart failure syndrome. J Cardiol. mai 2016; 67 (5): 406-11. 